\title{
Effects of Ultrasound Treatments on Antioxidants Content of Cider, Enriched Previously with Natural Extracts
}

\author{
BORIS BREZAN ${ }^{*}$,CARMEN LILIANA BADARAU ${ }^{2}$, ALEXANDRU WOINAROSCHY ${ }^{*}$, \\ VASILE PADUREANU ${ }^{2}$ \\ ${ }^{1}$ University Politehnica of Bucharest, Faculty of Applied Chemistry and Materials Science, 1-7 Polizu Str., 011061, \\ Bucharest, Romania \\ ${ }^{2}$ Transilvania University of Brasov, Food and Tourism Faculty, 148 Castelului, 500014, Brasov, Romania
}

\begin{abstract}
The cider obtained in laboratory conditions was enriched in valuable and natural bio compounds using several extracts (obtained from blueberry juice and an colorant obtained from black carrot "Black Carrot HC Red-Blue Colored Concentrate" in 2\% citric acid solution) and ultrasounds treatments.Compared with the untreated cider, all the cider variants enriched with both types of extracts had higher values for total polyphenols and flavonoids content. This increase in values, from one measurement to another is due to the increase in the amplitude of the ultrasound in the propagation medium (cider + liquid extract). This reveals the importance of increasing the amplitude, in the efficiency of extraction of anthocyanins, demonstrating that a similar application time, but at different amplitude, influences the content of polyphenols and flavonoids, respectively.To assess the antioxidant activity of the cider variants tested in the experimental study, it was estimated the diphenylpicrylhydrazyl (DPPH) free inhibition percentage (DPPH inhibition) by the enriched cranberry extracts obtained from the forest fruits (blueberries) in $2 \%$ citric acid, respectively by those obtained by using black carrot juice (0.03\% concentration).
\end{abstract}

Keywords: antioxidant compounds, cider, diphenylpicrylhydrazyl (DPPH)

\section{Introduction}

Over time, especially in recent years, the demand for minimally processed foods has led to significant changes in the techniques used, as some of them applied under certain critical conditions decreased the nutritional value of the product, and to the same extent its bioavailability, due to changes in physical or chemical nature, ultimately leading to reduced organoleptic acceptability.

The use of ultrasound is classified as a non-thermal processing method, with numerous advantages deriving from it, being in the same time one of the quickest techniques that have been developed to minimize processing, improve quality and protect food safety primarily [1,2]. All of these things, besides many alternatives they can offer, compared to conventional methods or techniques, since they can be used in the food industry from analysis to product modification $[3,4]$.

The paper wishes to reveal the importance of their application for the purpose of conducting a study on the potential for enrichment of cider by releasing phenolic compounds and anthocyanins, in the end.

The application of ultrasound in the case of liquids, as in the case of the present work, is based on the phenomenon of cavitation, which involves the formation, development and implosion of bubbles along with the generation and propagation of vibrations in the mass it crosses. The implosion, finally, causes mechanical (turbulent, shear), thermal and also chemical effects, with the generation of heat and pressure at the same time [1].

The work done for the experimental study focused on the following aspects:

- applying different ultrasound treatments (e.g. different amplitudes) in the case of improved cider samples by adding rich extract of antioxidant compounds initially (e.g. different extract volumes), 
- Physical Diphenylpicrylhydrazyl chemistry tests to get acquainted with the modification of the antioxidant content,

Abbreviation: TPC - total polyphenol content; TFC - total flavonoids content; DPPH Diphenylpicrylhydrazyl

\section{Material and methods}

\section{Collection and preparation of plant material}

The plant sources used to obtain the analyzed extracts to determine the content of polyphenols and flavonoids, respectively the assessment of antioxidant activity, were cranberries from Duke variety, purchased from the supermarket, culture origin, in a fresh state.

\section{Extraction}

Prior to extraction, the samples were cleaned and then wetted. A mass of freshly moistened samples $(50 \mathrm{~g})$ was added to the amount of solvent initially dosed $(200 \mathrm{~mL})$ in the sample mixing vessels, the mixture being subsequently stored at a temperature of $20^{\circ} \mathrm{C}$ for $24 \mathrm{~h}$. After this interval, the sample was subsequently shaken, using a Vortex shaker.

-Regarding the used solvents, extraction conditions that were applied to the plant source, makes direct reference to citric acid $2 \%$.

After the extraction was complete, the samples were centrifuged at 10,000 rpm, $15 \mathrm{~min}$.

All experiments were performed in three repetitions, and the results are expressed as mean value \pm standard deviation.

The main operations of the extraction scheme for polyphenols and flavonoids are shown in the following:

-samples homogenizing and stirring, subsequently added over the solvent,

-filtration, subsequently to $24 \mathrm{~h}$ storage of mixture at $20^{\circ} \mathrm{C}$,

-centrifugation, in order to collect the supernatant.

\section{Tested variants}

In order to carry out the experimental part, it was proceeded to use the cider obtained previously, in order to enrich it with a liquid extract concentrated in antioxidant compounds, obtained in laboratory conditions similar to the previous ones.

Various variants were tested, according to the following table:

Table 1. Cider variants with cranberry extract

\begin{tabular}{cccc}
\hline Coding & $\begin{array}{c}\text { Amplitude } \\
{[\%]}\end{array}$ & $\begin{array}{c}\text { Vol. of cider } \\
{[\mathrm{mL}]}\end{array}$ & $\begin{array}{c}\text { Vol. of extract } \\
{[\mathrm{mL}]}\end{array}$ \\
\hline \hline AM & - & 50 & 2.5 \\
\hline A1 & 20 & 100 & 5 \\
\hline A2 & 30 & 100 & 5 \\
\hline A3 & 40 & 100 & 5 \\
\hline A4 & 50 & 100 & 5 \\
\hline
\end{tabular}

$\overline{\mathrm{AM}}=$ witness tip sample; $\mathrm{A} 1 \ldots \mathrm{A} 4=1^{\text {st }}$ variant using cranberries extract... $4^{\text {th }}$ variant using cranberries extract etc.

Also, it was tested a colorant used at industrial level, named in international language "Colored Concentrate Black Carrot HC Red-Blue", manufactured by Dohler GMBH company in Darmstadt, Germany. Regarding the tested variants, table 2 contains details regarding cider additions 
Table 2. Cider variants with black carrot concentrated*

\begin{tabular}{cccc}
\hline Coding & $\begin{array}{c}\text { Amplitude } \\
{[\%]}\end{array}$ & $\begin{array}{c}\text { Vol. of cider } \\
{[\mathrm{mL}]}\end{array}$ & $\begin{array}{c}\text { Vol. of extract } \\
{[\mathrm{mL}]}\end{array}$ \\
\hline \hline $\mathrm{MM}$ & - & 50 & 2.5 \\
\hline $\mathrm{M} 1$ & 20 & 100 & 5 \\
\hline $\mathrm{M} 2$ & 30 & 100 & 5 \\
\hline $\mathrm{M} 3$ & 40 & 100 & 5 \\
\hline M4 & 50 & 100 & 5 \\
\hline (0.03\% concentration & & &
\end{tabular}

\section{Determination of Total Phenolic Content (TPC)}

Determination of total polyphenols content from extracts, involved:

- crushing the material and then, approx. $1 \mathrm{~g}$ of the product under test to be homogenized with 10 $\mathrm{mL} \mathrm{96 \%} \mathrm{ethanol,} \mathrm{shaken} \mathrm{vigorously} \mathrm{for} \mathrm{2-3} \mathrm{min} \mathrm{(Vortex)} \mathrm{and} \mathrm{filtered} \mathrm{through} \mathrm{a} \mathrm{strained} \mathrm{filter;} \mathrm{then,}$ $0.5 \mathrm{~mL}$ extract and $1.5 \mathrm{~mL}$ Folin Denis reagent (1:10) are introduced into a tube,

- standing for $5 \mathrm{~min}$ and then adding $2 \mathrm{~mL} \mathrm{7.5 \%} \mathrm{sodium} \mathrm{carbonate} \mathrm{solution,}$

- leaving to stand for $90 \mathrm{~min}$ and then read absorbance at 725 ,

- using the calibration curve the total polyphenol content was estimated.

For the determination of the calibration curve, necessary to estimate the content of polyphenols in samples, was used gallic acid (Roth, art no. 2699.1, Germany).

\section{Determination of Total Flavonoids Content (TFC)}

In order to determine the total flavonoids content, the material is crushed (if applicable) and then, 1 $\mathrm{g}$ of the product under test is homogenized with $10 \mathrm{~mL}$ of acidified ethanol (with $1 \% \mathrm{HCl}$ ), shaken vigorously for 2-3 min and filtered through a filter. For an extraction as advanced as possible, the operation can be repeated 2-3 times.

A $0.5 \mathrm{~mL}$ extract is introduced into a tube, over which $2 \mathrm{~mL}$ distilled water is added and then 150 $\mu \mathrm{L} 5 \% \mathrm{NaNO}$. Leave to rest for $6 \mathrm{~min}$. Then add 150 microliters of $10 \% \mathrm{AlCl}_{3}$ solution, leave to rest for $6 \mathrm{~min}$, add $2 \mathrm{~mL}$ of $2 \mathrm{NaOH}$ solution and after $15 \mathrm{~min}$ of rest read absorbance at $510 \mathrm{~nm}$ (Spectrophotometer DR2800 Hach Lange, USA), relative to distilled water. Using the calibration curve, the total flavonoid content is estimated.

Determination of the calibration curve required to estimate the flavonoids content of the samples, assumed the use of quercetin dihydrat.

\section{DPPH Activity}

An adapted method was used after Yi et all. (Yi Z., YU Y., Liang Y, Zeng B.2008, p. 597-603). After filtering the samples, in the alveoli of an ELISA plate with 96 wells, it was distributed using a pipette of 20 microlitres, distilled water and then 20 microlitres sample (filtered beforehand). There, were then added 200 microlitres of DPPH $0,3 \mathrm{mM}$ solution in each alveole. For controls, equal volumes of distilled water were used instead of the sample. The plates were incubated in the dark for $30 \mathrm{~min}$. The absorbance was read at $515 \mathrm{~nm}$ wavelength using the TecanSunRise reader (Magellan software).

The percentage of DPPH radicals inhibition was calculated using the formula:

$$
\% \text { DPPH inhibition }=[(\text { A control }- \text { A sample }) / \text { A control }] \times 100(\%)
$$

where A represents the absorbance read at 515nm [5]

\section{Results and discussions}

The values obtained represent the average of the readings, for absorbent samples at a wave length of $725 \mathrm{~nm}$. The figures vary quite a lot with each measurement, the results depending on the amplitude 
that was used. Maximum phenols were found in formulation consisting cider enriched with aqueous extract, and subject to a 50\% amplitude treatment. Table 3 describes the TPC for all tests carried out for cider enriched both with citric acid $2 \%$ and black carrot concentrated.

Table 3. Total phenolic content in analyzed ciders

\begin{tabular}{|c|c|c|c|c|c|c|}
\hline \multirow[b]{2}{*}{ SOLVENT } & \multirow[b]{2}{*}{ Sample } & \multirow{2}{*}{$\begin{array}{c}\text { Sample } \\
\text { volume } \\
{[\mathrm{mL}]}\end{array}$} & $\begin{array}{l}\text { Solvent } \\
\text { volume }\end{array}$ & \multicolumn{2}{|l|}{ Average } & \multirow[b]{2}{*}{$\begin{array}{c}\text { TPC, } \\
\text { mgAGE } / 100 \mathrm{~g}\end{array}$} \\
\hline & & & {$[\mathbf{m L}]$} & $\begin{array}{c}\text { Abs } \\
\text { 725nm }\end{array}$ & $\begin{array}{c}\text { TPC, } \\
\text { mg/mL }\end{array}$ & \\
\hline \multirow{5}{*}{ CITRIC ACID 2\% } & $\overline{\mathrm{AM}}$ & 1 & 10 & 0.753 & 0.320 & 319.90 \\
\hline & A1 & 1 & 10 & 0.824 & 0.353 & 353.36 \\
\hline & $\mathrm{A} 2$ & 1 & 10 & 0.861 & 0.370 & 370.48 \\
\hline & A3 & 1 & 10 & 0.939 & 0.407 & 407.39 \\
\hline & A4 & 1 & 10 & 1.940 & 0.879 & 878.89 \\
\hline \multirow{5}{*}{$\begin{array}{c}0.03 \% \text { BLACK } \\
\text { CARROT } \\
\text { CONCENTRATED } \\
\text { ADDITION }\end{array}$} & MM & 1 & 10 & 0.689 & 0.290 & 289.75 \\
\hline & M1 & 1 & 10 & 0.768 & 0.327 & 326.82 \\
\hline & M2 & 1 & 10 & 0.743 & 0.315 & 315.04 \\
\hline & M3 & 1 & 10 & 0.903 & 0.390 & 390.43 \\
\hline & M4 & 1 & 10 & 0.627 & 0.260 & 260.22 \\
\hline
\end{tabular}

On the other hand, table 4 compress the results that reveal the total content of flavonoids for the same variants of cider. We can state that we have obtained higher values from one measurement to another, for each of the ciders enriched with both types of extracts.

Table 4. Total flavonoids content in analyzed ciders

\begin{tabular}{|c|c|c|c|c|c|c|}
\hline SOLVENT & Sample & $\begin{array}{c}\text { Sample } \\
\text { vol. } \\
\text { [mL] }\end{array}$ & $\begin{array}{l}\text { Solvent vol. } \\
\qquad[\mathrm{mL}]\end{array}$ & $\begin{array}{c}\text { Average } \\
\text { Abs 510nm }\end{array}$ & $\mathrm{mg} / \mathrm{mL}$ & $\mathrm{mg} / 100 \mathrm{~g}$ \\
\hline \multirow{5}{*}{$\begin{array}{c}\text { CITRIC ACID } \\
2 \%\end{array}$} & 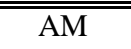 & 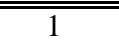 & 10 & 0.159 & 0.013 & 12.94 \\
\hline & A1 & 1 & 10 & 0.182 & 0.015 & 14.91 \\
\hline & $\mathrm{A} 2$ & 1 & 10 & 0.331 & 0.028 & 27.65 \\
\hline & A3 & 1 & 10 & 0.421 & 0.035 & 35.36 \\
\hline & A4 & 1 & 10 & 0.573 & 0.048 & 48.36 \\
\hline \multirow{5}{*}{$\begin{array}{l}0.03 \% \text { BLACK } \\
\text { CARROT } \\
\text { CONCENTRAT } \\
\text { ED ADDITION }\end{array}$} & MM & 1 & 10 & 0.135 & 0.011 & 10.88 \\
\hline & M1 & 1 & 10 & 0.230 & 0.019 & 18.96 \\
\hline & M2 & 1 & 10 & 0.268 & 0.022 & 22.22 \\
\hline & M3 & 1 & 10 & 0.326 & 0.027 & 27.19 \\
\hline & M4 & 1 & 10 & 0.193 & 0.016 & 15.85 \\
\hline
\end{tabular}


This increase in values, from one measurement to another, is due to the modification (growth) of the ultrasound amplitude in the propagation medium (cider plus liquid extract). This reveals the importance of increasing amplitude in streamlining the extraction of anthocyanin compounds, demonstrating that a similar application time, but at a different amplitude, influences the content in phenols, respectively flavonoids. The best results in the extraction of phenols and flavonoids from the ciders enriched with cranberry extract were obtained using a amplitude of $50 \%$ in both cases. In the same time, in the case of extraction of phenols and flavonoids from the ciders enriched with black carrot extract, they were obtained using a amplitude of $40 \%$ in both cases.

For the appreciation of the antioxidant activity of the cider variants tested in the experimental study, it was used as reagent, the DPPH. More specifically, it was estimated the percentage of inhibition of DPPH free radicals (\% DPPH inhibition) by ciders enriched with extracts obtained from berries (blueberries) in $2 \%$ citric acid, respectively with those obtained by using the Black carrot concentrate.

Table 5 shows the average of the values for repetitions of readings at wavelength of $515 \mathrm{~nm}$, respectively the percentage of DPPH inhibition, for berries, but also for the black carrot concentrate.

Table 5. Percentage of DPPH inhibition for berries and black carrot

\begin{tabular}{|c|c|c|c|}
\hline \multirow[b]{2}{*}{ SOLVENT } & \multirow[t]{2}{*}{ Sample } & \multicolumn{2}{|c|}{ Values of AsIsum } \\
\hline & & AVERAGE & $\begin{array}{l}\% \text { inh } \\
\text { DPPH }\end{array}$ \\
\hline \multirow{5}{*}{ CITRIC ACID $2 \%$} & $\mathrm{AM}$ & 0.373 & 72.83 \\
\hline & $\mathrm{A} 1{ }^{--}$ & $0.419^{-}$ & -69.46 \\
\hline & $\mathrm{A} 2$ & 0.366 & 73.32 \\
\hline & $\mathrm{A} 3$ & 0.346 & 74.82 \\
\hline & $\mathrm{A} 4$ & 0.394 & 71.28 \\
\hline \multirow{5}{*}{$0.03 \%$ BLACK CARROT CONCENTRATED ADDITION } & MM & 0.307 & 77.61 \\
\hline & $\mathrm{Mr}^{-}$ & 0.306 & 77.70 \\
\hline & $\mathrm{M} 2$ & 0.450 & 67.22 \\
\hline & $\mathrm{M} 3$ & $0.315^{-}$ & 77.02 \\
\hline & $\mathrm{M}^{-}$ & 0.373 & 72.83 \\
\hline
\end{tabular}

\section{Conclusions}

The content of the works incorporates the potential application of ultrasounds in order to improve the chemical profile of the cider (direct reference to the compounds of the antioxidant nature) and the mechanisms of the phenomenon, with direct reporting to the cider.

The study reveals importance of ultrasounds application for increasing content in such compounds, considering its application to different amplitudes. The explanation is the partitionation of the molecules present in the initial sample, followed by the intensification of the activity of these compounds in the end, as a result of their division (e.g. shear).

A linear increase in the temperature is observed in both variants of cider, which is due to the increase of the amplitude of ultrasounds. Once we increase the amplitude, it occurs the increase in the temperature of the ultrasonicated environment, and figure 1 showing the changes in this direction. That's why, side effects of their use, on other cider compounds, can be taken into account in future studies, as long as temperature in range of $50-60{ }^{\circ} \mathrm{C}$ were achieved. 


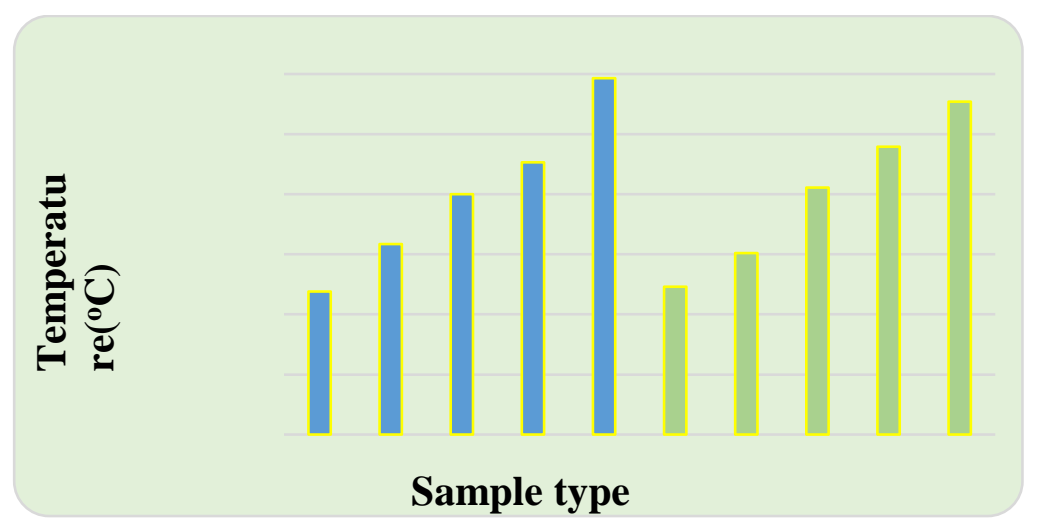

Figure 1. Temperature modification during ultrasonication

\section{References}

1.GALLO, M., FERRARA, L., NAVIGLIO, D., Foods, 7, 2018 p. 164

2.SAHIN, S., E., SOYSALM, C, Use of ultrasound in food preservationm, University of Gaziantep, Gaziantep, Turkey, 2018;

3.***https://www.sciencedirect.com/science/article/pii/S2210784314000461

4.***https://www.ijcmas.com/7-7-2018/Rishi\%20Kumar\%20Puri,\%20et\%20al.pdf

5.AWAD, T., S., MOHARRAM, H., A., SHALTOUT, O., E., ASKER, D., YOUSSEF M., M., Food Research International, 48, no. 2, 2012, p. 410

$\overline{\text { Manuscript received: } 26.11 .2019}$ 